\title{
25 Research Square \\ Augmented Rehabilitation Program for Young Patients Following Total Hip Arthroplasty
}

\author{
Ahmed Negm \\ University of Alberta \\ Milad Yavarai \\ University of Alberta \\ Gian Jhangri \\ University of Alberta \\ Robert Haennel \\ University of Alberta \\ Allyson Jones ( $\square$ cajones@ualberta.ca ) \\ University of Alberta
}

\section{Research Article}

Keywords: Hip, replacement, arthroplasty, rehabilitation, surgery, exercise

Posted Date: January 5th, 2021

DOI: https://doi.org/10.21203/rs.3.rs-138081/v1

License: (c) (i) This work is licensed under a Creative Commons Attribution 4.0 International License. Read Full License 


\section{Abstract}

\section{Background}

The increase rate seen in Total Hip Arthroplasty (THA) for younger patients has implications for future rehabilitation demands for primary and revision THA surgery. This study aims to determine the impact of a 6week post-operative rehabilitation program designed for THA patients $\leq 60$ years on physical activity (PA) and function compared to age- and a sex-matched control group received usual postoperative care at 12-week postTHA.

\section{Methods}

In this quasi-experimental study, a cohort of THA candidates was recruited during their 6-week postoperative visit to their surgeons. The out-patient rehabilitation program consisted of 12 structured exercise classes ( $2 \mathrm{hrs} / \mathrm{class})$ over 6 weeks. Physical activity was assessed using Sense Wear Pro Armband ${ }^{\mathrm{TM}}$ [SWA]. Participants completed the Hip Osteoarthritis Outcome Score (HOOS), and THA satisfaction questionnaire before and immediately after the intervention.

\section{Results}

The intervention group took significantly more steps/day at the follow-up compared to baseline. The intervention group had a higher mean change in the number of weekly PA bouts than the control group. Within the intervention groups, all HOOS subscales were significantly higher at the follow-up compared to baseline.

\section{Conclusion}

The augmented rehabilitation program may have immediate effects on pain relief and symptom reduction for patients ( $\leq 60$ years) following THA.

\section{Background}

In 2017-2018, approximately 53,217 elective total hip arthroplasty (THA) were performed in Canada, representing a $17.4 \%$ increase over the past 5 years (1). Of the hip arthroplasty hospitalizations, $18,920(32.3 \%)$ were under the age of 65 and an increased number of younger patients are now undergoing hip arthroplasty. By $2030,52 \%$ of primary THAs are projected to be implanted in patients younger than 65 years, with the strongest increase in patients aged $45-55$ years $(2,3)$. This increase in THA in younger patients may play a role in future rehabilitation demands for primary and revision THA surgery (4).

Osteoarthritis (OA) is the most common reason for patients older than 60 years of age to undergo THA (5). Although OA is still the primary reason for THA with younger patients (4), they require THA for several other conditions such as osteonecrosis, Rheumatoid Arthritis, hip dysplasia, a slipped epiphysis, and Perthes disease, congenital hip luxation, tumors, and infection $(1,4,6,7)$. Regardless of age, symptoms for elective THA remain similar in that severe pain, limitation of range of motion (ROM), and dysfunction are the primary rationale for THA (8). The THA implant longevity and the possibility of subsequent revision is a major concern with young patients. Although the longevity of THA is approximately $15-20$ years (9-11), younger patients are more likely to place increased demands on the implant, in particular the bearing surfaces (12). 
The primary aim of rehabilitation for recovery after THA is to optimize physical function, strength, and pain. A systematic review based on 5 studies for 234 participants showed that 8-12 weeks of physiotherapy interventions improved hip abductor strength by a mean of 16 Nanometer $(\mathrm{Nm})(95 \% \mathrm{Cl} 10,22)$, gait speed by $6 \mathrm{~m} / \mathrm{min}(95 \% \mathrm{Cl} 1,11)$ and cadence by 20 steps/min $(95 \% \mathrm{Cl} 8,32)(13,14)$. Functional gains can also be seen during recovery. A randomized controlled trial of 28 older participants found that an eight-week strengthening program improved the 6-minute walk distances at 12 and 24 weeks post-THA (14). Improvements with hip muscle strength, postural stability, and self-perceived function compared to the control group were seen at 4-12 months after surgery (15).

Overall, the effect of rehabilitation programs on the recovery with THA have primarily been based on findings with older patients. Studies examining specific exercise programs for younger patients are limited. A randomized control trial that examined the effect of a 4-week strengthening intervention after THA in patients 60 years or younger reported that a combined rehabilitation program increased leg strength when compared to conventional rehabilitation alone (16). This study showed that maximal strength training programs and an aerobic endurance training program are required for full recovery following THA in patients 60 years or younger (16).

Although substantial gains are seen with pain relief and functional improvement for THA (17), it is less clear that patients will become more mobile and return to an active lifestyle (18). Evidence has shown that activity does not innately improve after total joint replacement when pain is relieved and function improved $(19,20)$. Evidence and clinical guidelines generally support low impact physical activity for THA (21); however, studies examining physical activity and function of younger patients following THA are lacking. A rehabilitation program specifically directed at younger patients recovering from THA is warranted given the special needs of this patient group regarding an active lifestyle and return to work.

The primary aim of this study is to determine the feasibility of a 6-week post-operative rehabilitation program specifically designed for THA patients 60 years of age or younger on physical activity, self-reported hip pain, and function. The secondary objectives are 1) to examine the correlation between physical activity and self-reported pain and function, and 2) to assess participants' satisfaction with THA.

\section{Materials}

\section{Study Design}

Using a quasi-experimental study design, we compared a 6-week post-operative augmented rehabilitation to usual care among people who were 60 years or younger and undergoing elective THA. Participants were recruited from a central intake centre, Edmonton Hip and Knee Clinic which serves Edmonton Alberta, Canada, and surrounding regions. With over 35 surgeons and multi-disciplinary teams, approximately 3000 joint replacements are performed annually. Most, if not all, surgeons were high volume (> 50 THA per year) who routinely used the Hardinge approach. All patients followed a provincial standardized clinical pathway for acute-care management with 3 to 4 days of hospital stay. The home exercise program which is provided as usual care included range of motion activities, isometric hip strengthening exercises, and walking with appropriate assistive walking devices.

Eligible participants were a) 60 years of age or younger, b) received a unilateral THA, c) 6-12 weeks follow-up after receiving an elective THA, and d) able to communicate in English. The exclusion criteria consisted of a) 
bilateral THA, b) hemiarthroplasties, c) emergency THA, d) primary diagnosis of developmental hip dysplasia, and e) patients who have a systemic illness that limited their ability to participate (e.g., rheumatoid arthritis, cardiac involvement that precluded exercise).

Upon providing written consent, patients were assessed at their 6-week post-operative visit with the surgeon (baseline assessment) and then 6 weeks later when the interventional group had completed the rehabilitation program (Follow-up assessment) (FIGURE 1). The assessment consisted of socio-demographic (age, sex, education, marital status), medical/surgical information, physical activity (SenseWear Pro Armband (SWA) (2225), pain and function (Hip Osteoarthritis Outcome Score, HOOS (26)) and participants' satisfaction with THA. Using a standardized form, clinical charts were reviewed for medical and surgical information (chronic conditions, height/weight, surgical approach, complications). This study was approved by the University of Alberta's Health Ethics Board. (PRO00051978). All procedures were performed in accordance with University of Alberta's Health Ethics Board guidelines.

\section{Augmented Rehabilitation Program}

The intervention group consisted of participants who were referred to a post-operative augmented 6-week rehabilitation program by their surgeons at the 6 -week post-operative routine visit. The outpatient rehabilitation program involved 2 hours of structured group exercise classes led by a physiotherapist over 6 weeks. Participants were required to attend twice a week for 12 sessions. Each session included 1 hour of land-based exercises and 1 hour of water-based exercises.

\section{Usual Post-operative Care for Control Group}

At the 6-week routine post-operative surgical visit, age (within a 5-year age difference) and sex-matched participants were recruited for the control group. Participants in the control group continued with usual care after their six-week surgeon's visit, which included a standardized home exercise.

\section{Outcomes Measures}

Physical Activity (PA): A direct measure of daily PA was estimated from the daily energy expenditure calculated from the SenseWear Pro Armband ${ }^{\mathrm{TM}}$ (SWA; Body Media, Inc, Pittsburgh, PA). The SWA is a tri-axial accelerometer that integrates motion sensor data with the data from three sensors (heat flux, galvanic skin response, and skin temperature) and combines these data with demographic characteristics (gender, height, weight, handiness, and smoking status) to estimate energy expenditure using algorithms provided by the manufacturer (22-25). The SWA has been shown to have good validity under both laboratory $(22,27,28)$ and free-living conditions $(29)$. There is an error rate of $8 \%$ with an ICC of 0.8 for energy expenditure determined from the SWA and doubly labeled water (30).

The SWA was worn on the arm over the triceps for four consecutive days (31). Participants were instructed to remove the device when bathing, showering, or swimming. Valid days were defined as those days when the participant wore the SWA $>10$ hours during the waking time $(32,33)$. Once the SWA was returned to the lab, data 
were downloaded to generate the total time the device was worn, steps/minute, and minute by minute energy expenditure, and metabolic equivalent task (MET) intensity levels. One MET is the energy cost of resting quietly, often defined in terms of oxygen uptake as $3.5 \mathrm{~mL} / \mathrm{kg} / \mathrm{min}(34,35)$. Minute by minute data was averaged over all valid days to provide information on the number of steps/day, energy expenditure, stationary time, and time spent in different activity intensities (i.e., light PA, moderate-vigorous PA [MVPA]).

Stationary time was defined as waking time with an energy expenditure $\leq 1.5$ METs (36-38). Light Physical Activity was defined as activities that required an energy expenditure of 1.6-2.9 METs (e.g., activities of daily living [ADL]) (37). MVPA included activities with an energy expenditure $\geq 3.0$ METs. For time spent in MVPA, recommendations suggested PA bouts of $\geq 10$ minutes $(39,40)$. Data were inspected to determine both the total minutes of MVPA (MVPA ${ }_{\text {all }}$ ) and continuous MVPA occurring in $>10$ minutes bouts (i.e., MVPA ${ }_{10+}$ ). To count as an $\mathrm{MVPA}_{10+}$ the bout had to start with a minute above the MVPA cut-point ( $\geq 3$ METs) and last for $>10$ consecutive minutes with allowance for a maximum of two observations falling below the cut-point during the period (i.e., 8/10 minutes) (41). Furthermore, we calculated the amount of time and energy spent in $\mathrm{MVPA}_{10+}$. The amount of energy spent on MVPA ${ }_{\text {all }}$ was also presented as PA energy expenditure.

Hip Osteoarthritis Outcome Score (HOOS): The HOOS questionnaire is a self-report measure of joint-specific pain, stiffness, sports activity, and health-related quality of life. It consists of 5 subscales: Pain (10 items), Symptoms (2 items), Function in activities of daily living (ADL) (17 items), Function in sport and recreation (Sport/Rec) (4 items), and hip-related Quality of life (QoL) (4 items). Each subscale score is calculated independently by summing all items in each subscale and then normalizing the total into the range of 0 to 100 (26). The higher score reflects better condition for the hip. The validity, reliability, and responsiveness of HOOS had been evaluated in different studies $(26,42,43)$. HOOS contains adequate measurement qualities to evaluate patients with hip osteoarthritis or THA (43) and patients $\leq 66$ years of age reported higher responsiveness in all five subscales compared to patients $>66$ years of age (26).

Participants' satisfaction with THA: Participants' satisfaction was assessed using a 5 -item questionnaire asking if THA: could be recommended to their family, was worthwhile, was helpful, led to a negative outcome, or was dissatisfying (44). All items were rated on a 5-point likert scale ranging from strongly agree to strongly disagree

\section{Data analysis}

Summary descriptives were reported as mean and standard deviation (SD) for continuous variables, numbers, and percentages for categorical variables. The between-group differences at baseline, follow-u,p, and the absolute change (follow-up - baseline) were evaluated by using two independent samples t-tests. To evaluate the within-group differences, paired-samples t-tests were used. Mann-Whitney U nonparametric test was used to compare the groups if data is not normally distributed. To explore whether the physical activity as measured by the SWA (step counts and MVPA bouts) were correlated with the self-reported HOOS subscale scores, Pearson correlation coefficients were examined and categorized as weak ( 0.10 to 0.39$)$, moderate ( 0.40 to 0.69 ), strong ( 0.70 to 0.89$)$ and very strong $(0.90$ to 1.00$)$. (45). Statistical analyses were conducted using SPSS version 24 (SPSS, Inc. Chicago, IL, USA). 
Of the 24 participants recruited, 14 participants received the augmented rehabilitation and 10 participants were in the control group. The groups were comparable with respect to age, gender, marital status, living status, and education ( $p>0.05$ ) (Table 1). The control group, however, had a higher BMI compared to the augmented rehabilitation group (mean difference $4.2 \mathrm{~kg} / \mathrm{m}^{2} ; 95 \% \mathrm{Cl} 0.2,8.3$ ). The median number of comorbidities was significantly higher in the control group (4, IQR 3 to 5)) than in the augmented rehabilitation group (2, IQR 1 to 2$)$ $(p=0.01)$. The most frequent conditions were chronic back/neck pain $(14,58 \%)$ and mental health problems $(9$, $38 \%$ ) (Table 1). No postoperative surgical complications were reported. The length of stay for both groups was 3 to 4 days. All participants in the intervention group tolerated and were adherent to the rehabilitation program without adverse events. Thirteen out of the fourteen intervention group participants completed at least $80 \%$ of the intervention sessions. 
Table 1

Baseline characteristics of participants.

\begin{tabular}{|c|c|c|}
\hline & $\begin{array}{l}\text { Intervention } \\
(n=14)\end{array}$ & $\begin{array}{l}\text { Control } \\
(n=10)\end{array}$ \\
\hline \multicolumn{3}{|l|}{ Demographics } \\
\hline Age (years), mean $\pm S D$ & $51.9 \pm 4.1$ & $54.5 \pm 5.2$ \\
\hline Employment Status, $n$ (\%) & $10(71 \%)$ & $5(50 \%)$ \\
\hline Employed full-time & $0(0 \%)$ & $1(10 \%)$ \\
\hline Employed part-time & $1(7 \%)$ & $0(0 \%)$ \\
\hline Unemployed & $2(14 \%)$ & $1(10 \%)$ \\
\hline Disability & $1(7 \%)$ & $3(30 \%)$ \\
\hline \multicolumn{3}{|l|}{ Retired } \\
\hline \multicolumn{3}{|l|}{ Gender, $n(\%)$} \\
\hline Female & $5(35)$ & $3(30)$ \\
\hline \multicolumn{3}{|l|}{ Marital Status, $n(\%)$} \\
\hline Married/ common-law & $12(86)$ & $9(90)$ \\
\hline Education (years of school), mean $\pm S D$ & $14 \pm 2.3$ & $14.1 \pm 2.5$ \\
\hline \multicolumn{3}{|l|}{ Living Status, living with, $n(\%)$} \\
\hline Alone & $1(7)$ & 0 \\
\hline Spouse and/or others & $13(93)$ & $10(100)$ \\
\hline \multicolumn{3}{|l|}{ Medical } \\
\hline$B M I\left(\mathrm{~kg} / \mathrm{m}^{2}\right)$ mean $\pm S D$ & $27 \pm 4.1$ & $31.2 \pm 5$ \\
\hline \multicolumn{3}{|l|}{ Comorbidity } \\
\hline Number of co-morbidity/person, median (25\%ile, $75 \%$ ile) & $2(1,2)$ & $4(3,5)$ \\
\hline \multicolumn{3}{|l|}{3 Most Prevalent Comorbidities } \\
\hline Chronic Pain, n (\%) & $8(57)$ & $6(60)$ \\
\hline Back & 7 & 4 \\
\hline Neck & 2 & 4 \\
\hline Mental Health Problem, n (\%) & $4(29)$ & $5(50)$ \\
\hline Depression & 4 & 2 \\
\hline Anxiety & 3 & 2 \\
\hline
\end{tabular}

SD: standard deviation, BMI: Body mass index 


\begin{tabular}{|lll|}
\hline & $\begin{array}{l}\text { Intervention } \\
(\mathbf{n = 1 4})\end{array}$ & $\begin{array}{c}\text { Control } \\
(\mathbf{n}=10)\end{array}$ \\
\hline Panic & 1 & 2 \\
\hline High Blood Pressure, $\mathrm{n}(\%)$ & $4(29)$ & $3(30)$ \\
\hline Ambulation status, $\mathrm{n}(\%)$ & & \\
\hline Distance walk<1 block & $1(7)$ & $0(0)$ \\
Distance walk 1-5blocks & $4(29)$ & $6(60)$ \\
Distance walk 6-10blocks & $4(29)$ & $1(10)$ \\
Distance walk unlimited & $5(36)$ & $3(30)$ \\
\hline Surgical characteristics & & $8(80 \%)$ \\
\hline Type of Arthroplasty, $n$ (\%) & $11(79 \%)$ & $2(200 \%)$ \\
Non-cemented & $2(14 \%)$ & 0 \\
\hline Hybrid & $1(7 \%)$ & \\
Cemented & & $1(10)$ \\
\hline Surgical Approach, $n$ (\%) & & $4(40)$ \\
\hline Antero-lateral hip & $2(14)$ & $5(50)$ \\
\hline Posterior-lateral hip & $9(65)$ & $3(21)$ \\
\hline Unknown & & \\
\hline SD: standard deviation, BMl: Body mass index & & \\
\hline
\end{tabular}

\section{Physical Activity}

The mean wearing time of the SWA for the entire cohort was approximately 15 hours/day over 4 consecutive days regardless of group. Table 2 summarizes the physical activity profile of the study groups at baseline and follow-up assessments. After 6 weeks of augmented rehabilitation, the intervention group took more steps/day compared to their baseline (mean difference $=2,440$ steps/day, $95 \% \mathrm{Cl}=1678,4712)(\mathrm{p}<0.05)$, although the daily step count of 10,000 steps was still below the recommended daily steps for adults ( (46). In contrast, the mean daily step count for the control group showed no significant difference over time (mean difference $=573$ steps/day, 95\% Cl= -1682, 2828) $(p=0.60)$. (Table 2$)$. 
Table 2

Comparisons of physical activity measures within groups at baseline and follow-up.

\begin{tabular}{|c|c|c|c|c|c|c|}
\hline \multirow[b]{2}{*}{ Physical activity Measures } & \multicolumn{3}{|c|}{$\begin{array}{l}\text { Intervention }(n=14) \\
\text { Mean } \pm \text { SD }\end{array}$} & \multicolumn{3}{|c|}{$\begin{array}{l}\text { Control }(n=10) \\
\text { Mean } \pm \text { SD }\end{array}$} \\
\hline & Baseline & Follow-up & $\begin{array}{l}\mathrm{p}- \\
\text { value }\end{array}$ & Baseline & Follow-up & $\begin{array}{l}\mathrm{p}- \\
\text { value }\end{array}$ \\
\hline Waking wearing time (Hrs/day) & $14.9 \pm 1.5$ & $14.7 \pm 1.4$ & 0.658 & $15.6 \pm 1.4$ & $15.3 \pm 1.2$ & 0.782 \\
\hline Sleeping time (Hrs/day) & $5.8 \pm 1.9$ & $4.7 \pm 1.1$ & 0.058 & $6.0 \pm 1.0$ & $5.2 \pm 1.0$ & 0.050 \\
\hline Step (counts/day) & $\begin{array}{l}4156 \pm \\
2460\end{array}$ & $\begin{array}{l}6596 \pm \\
3325\end{array}$ & 0.005 & $\begin{array}{l}5282 \pm \\
2720\end{array}$ & $\begin{array}{l}5855 \pm \\
2031\end{array}$ & 0.439 \\
\hline Stationary time (Hrs/day) & $10.8 \pm 2.1$ & $10.1 \pm 2.1$ & 0.120 & $10.5 \pm 2.3$ & $10.5 \pm 1.8$ & 0.906 \\
\hline Mild Activity (Hrs/day) & $2.9 \pm 1.2$ & $3.1 \pm 0.9$ & 0.496 & $3.6 \pm 1$ & $3.6 \pm 1.4$ & 0.889 \\
\hline MVPA (Hrs/day) & $1.1 \pm 1$ & $1.6 \pm 1.4$ & 0.085 & $1.5 \pm 1.1$ & $1.3 \pm 0.7$ & 0.463 \\
\hline $\begin{array}{l}\text { Weekly Number of bouts } \geq 10 \text { min } \\
\text { at MVPA }\end{array}$ & $\begin{array}{l}14.8 \pm \\
14.6\end{array}$ & $\begin{array}{l}21.0 \pm \\
29.2\end{array}$ & 0.286 & $\begin{array}{l}20.4 \pm \\
16.5\end{array}$ & $11.3 \pm 8.6$ & 0.110 \\
\hline Duration of MVPA bout & $13.0 \pm 4.1$ & $\begin{array}{l}16.9 \pm \\
13.4\end{array}$ & 0.402 & $15.1 \pm 3.9$ & $\begin{array}{l}18.4 \pm \\
10.6\end{array}$ & 0.100 \\
\hline DEE (kcal/day) & $\begin{array}{l}2184 \pm \\
470\end{array}$ & $\begin{array}{l}2227 \pm \\
446\end{array}$ & 0.531 & $\begin{array}{l}2686 \pm \\
768\end{array}$ & $\begin{array}{l}2546 \pm \\
714\end{array}$ & 0.316 \\
\hline All PAEE > 3 METs (kcal/day) & $322 \pm 252$ & $445 \pm 261$ & 0.073 & $557 \pm 474$ & $477 \pm 285$ & 0.506 \\
\hline
\end{tabular}

The intervention group had a higher mean change in the number of MVPA bouts $(6.2, S D=20.7)$ than the control group $(-9.2, S D=16.4)(p=0.05)$. The average time spent in each MVPA bout at baseline and follow up was 15.1 \pm 4 min and $18.4 \pm 10.6$ min for the control group and $13.7 \pm 4.1$ and $17.2 \pm 13.4$ for the intervention group. Although the average time spent in the bouts was not statistically different between groups. No significant differences were seen between the intervention and control groups for any other parameters measured by the SWA.

\section{Patient-reported Outcome Measures}

The intervention group showed significant differences in all subscales of the HOOS over time, whereas the ADL subscale was the only significant difference seen with the control group (Table 3). At baseline, the control group $(78.5 \pm 18.4$ ) had fewer symptoms (HOOS Symptom) than the intervention group $(63.9 \pm 14.3)(p=0.04)$. The mean change in the symptoms and pain HOOS subscale were significantly higher in the intervention compared to the control group. At the follow-up assessment, the Sport/recreation subscale was significantly higher in the intervention group $(79.9 \pm 16.7)$ compared to the control group (, $57.5 \pm 26.0)(p=0.02)$ (Table 3). Only the intervention group showed a clinically important change compared to their baseline in ADL, QoL, and sport/rec, however, there was no clinically important change in the control group (47). While most correlations between the HOOS and daily step count or the number of weekly MVPA bouts were weak $(r=0.1-0.39)$, moderate correlations 
$(r=0.4-0.69)$ were seen between the HOOS-QoL subscale and step counts $(r=0.49)$, and the number of MVPA bouts $(r=0.53)(45)$.

Table 3

Comparisons of HOOS scores within groups and between groups

\begin{tabular}{|c|c|c|c|c|c|c|c|c|c|}
\hline \multirow[b]{2}{*}{$\begin{array}{l}\text { HOOS } \\
\text { Scores }\end{array}$} & \multicolumn{3}{|c|}{$\begin{array}{l}\text { Intervention }(n=14) \\
\text { Means } \pm \text { SD }\end{array}$} & \multicolumn{3}{|c|}{$\begin{array}{l}\text { Control }(n=10) \\
\text { Means } \pm \text { SD }\end{array}$} & \multicolumn{3}{|c|}{ Between groups p-value } \\
\hline & Baseline & $\begin{array}{l}\text { Follow- } \\
\text { up }\end{array}$ & $\begin{array}{l}\text { Within- } \\
\text { group } \\
\mathrm{p} \text { - } \\
\text { value }\end{array}$ & Baseline & $\begin{array}{l}\text { Follow- } \\
\text { up }\end{array}$ & $\begin{array}{l}\text { Within- } \\
\text { group } \\
\text { p- } \\
\text { value }\end{array}$ & Baseline & $\begin{array}{l}\text { Follow- } \\
\text { up }\end{array}$ & $\begin{array}{l}\text { Mean } \\
\text { change }\end{array}$ \\
\hline Pain & $\begin{array}{l}74.2 \pm \\
20.2\end{array}$ & $\begin{array}{l}91.7 \pm \\
8.6\end{array}$ & 0.005 & $\begin{array}{l}80.6 \pm \\
18\end{array}$ & $\begin{array}{l}83.6 \pm \\
14.5\end{array}$ & 0.387 & 0.436 & 0.141 & 0.029 \\
\hline Symptom & $\begin{array}{l}63.9 \pm \\
14.3\end{array}$ & $\begin{array}{l}82.9 \pm \\
9.7\end{array}$ & $\begin{array}{l}<.001 \\
0.01\end{array}$ & $\begin{array}{l}78.5 \pm \\
18.4\end{array}$ & $\begin{array}{l}84.5 \pm \\
10.9\end{array}$ & 0.250 & 0.040 & 0.305 & 0.037 \\
\hline ADL & $\begin{array}{l}73.1 \pm \\
16.3\end{array}$ & $\begin{array}{l}89.1 \pm \\
7.7\end{array}$ & 0.003 & $\begin{array}{l}74.3 \pm \\
18.5\end{array}$ & $\begin{array}{l}83.1 \pm \\
13.1\end{array}$ & 0.022 & 0.873 & 0.172 & 0.207 \\
\hline Sport & $\begin{array}{l}42.0 \pm \\
26.1\end{array}$ & $\begin{array}{l}79.9 \pm \\
16.7\end{array}$ & $\begin{array}{l}<.001 \\
0.001\end{array}$ & $\begin{array}{l}43.8 \pm \\
29.2\end{array}$ & $\begin{array}{l}57.5 \pm \\
26.0\end{array}$ & 0.312 & 0.876 & 0.017 & 0.117 \\
\hline Hip QoL & $\begin{array}{l}42.9 \pm \\
19.0\end{array}$ & $\begin{array}{l}63.4 \pm \\
17.7\end{array}$ & 0.007 & $\begin{array}{l}53.8 \pm \\
22.5\end{array}$ & $\begin{array}{l}61.3 \pm \\
18.6\end{array}$ & 0.161 & 0.212 & 0.777 & 0.122 \\
\hline
\end{tabular}

All 24 participants in this study were satisfied with the THA surgery procedure they had undergone. At the followup assessment, 12 (86\%) patients in the intervention group and $9(90 \%)$ in the control group strongly agreed with the statements that "I would recommend a hip replacement to my family if they needed care for hip arthritis" and "I feel the hip replacement surgery was worthwhile". At follow up assessment, 2 (20\%) of the control group and 2 $(14 \%)$ of the intervention group were dissatisfied with the functioning of the hip that received the replacement.

\section{Discussion}

Improvements were seen with the augmented rehabilitation program with step count, pain (HOOS symptom), and a greater change in MVPA bouts of activity. All participants regardless of the group were satisfied with their THA surgery.

Other studies that have examined step count in younger patients recovering from THA reported fewer daily steps at 6 months after surgery (48). In comparison to our intervention group, Fujita et al., reported lower step counts (5,657 steps), light activity (107 min/day), and MVPA (17 min/day) at 6 months after THA.) (49). The differences in step counts and MVPA bouts could be due to the diversity in methods of measuring objective physical activity, such as pedometers (49), mobile step-tracking applications (48), or accelerometer. A systematic review and meta-analysis examined the changes in PA after total joint replacement and included 7 studies (336 participants) 
(50). This review showed that there was no significant increase in PA at 6 months when compared to baseline (SMD 0.1, 95\% Cl $=0.1,0.3$ ) and large improvements in self-reported physical function (SMD $0.9,95 \% \mathrm{Cl} 0.1,1.8$ ) (50). The lack of increased PA that was shown in our results and Hammett et al (50) could be behavioral in nature, as a sedentary lifestyle is difficult to change. Future studies that focus on changing sedentary behavior are needed.

The Canadian physical activity guidelines for adults aged 18-64 years include at least 150 minutes of MVPA per week to achieve health benefits(51). The average time patients in the intervention group spent on MVPA daily was approximately $176.2 \mathrm{~min} /$ week and they met the guideline determined by the Canadian Society for Exercise Physiology (CSEP)(51). Compared to the control group, the intervention group has more MVPA bouts per week (21.0 versus 11.3) at the follow-up assessment than the control group. After accounting for baseline differences, there were statistically significant differences in MVPA bouts between groups. These between-group differences appear to be clinically important and show the potential effectiveness of the intervention.

The positive effects of the augmented rehabilitation we found may be attributed to a few features of the program such as structured classes led by physiotherapists, high-intensity activities, and available equipment. A systematic review found that the center-based exercise rehabilitation is more effective than the home-based exercise for THA patients' recovery (52) because of the higher training intensity and access to professional supervision, specialized equipment, and facilities in center-based exercise (52). Hydrotherapy with OA has positive effects to reduce pain (SMD $=-.4 ; 95 \% \mathrm{Cl}=-0.6$ to -0.2$)$ and to improve physical function $(\mathrm{SMD}=0.3$, $95 \% \mathrm{Cl}=0.1-0.5)$ for adults with musculoskeletal conditions (53). Exercise in water offloads weight-bearing and may allow people with hip pain, swelling, leg weakness to exercise successfully when this may not be possible on land (54-56). Thirdly, as the PA guidelines recommended, it is beneficial to add muscle and bonestrengthening activities to the exercise regimen for people aged 60 years or younger (57).

The primary clinical goals of joint replacement surgery are pain relief and functional improvement. More recently, physical activity has become another outcome. Others have shown a weak to moderate correlation between PA using an accelerometer and self-reported PA questionnaires in people with hip OA and Post-THA (58). We found similar findings in that the correlation between the bouts of MVPA and step count did not correlate with selfreported pain, and function, yet moderate correlations were seen with the HOOS QoL and step counts and MVPA bouts (45). This correlation confirms the results of previous population-based studies that showed an association between health-related quality of life and physical activities $(59,60)$.

In recent years, the length of hospital stay post-THA has been reduced to 3-4 days which can be attributable to advances in surgical and prosthetic technologies. The ramification of an earlier hospital discharge is that the recovery time with a specialized care team and active rehabilitation has been limited (61). At discharge, patients receive a guide for continuing strengthening, stretching, and ambulation exercises; however, they are expected to complete this exercise program independently. In a prospective study, it was reported that many patients would have liked to spend more time with their physiotherapists which could be due to insecurities or lack of confidence of the patient in performing activities alone $(61,62)$. The proposed post-operative rehabilitation program provides additional contact and supervised exercise time with physiotherapists, which may be necessary beyond the limited length of stay, to enable patients to return to full activity. 
By tailoring and implementing an augmented THA rehabilitation program to younger patients ( $\leq 60$ years), a precision medicine approach may be used to tailor pre- or post-operative rehabilitation intervention to prevent potential deleterious outcomes for this population. There is a growing need to transform our healthcare delivery system from a reactive approach to a more personalized system of predictive, preventive, and precision healthcare by integrating evidence-based medicine and precision diagnostics into clinical practice (63). After the implementation of tailored post-operative rehabilitation programs for patients at risk, this research program has the potential of preventing post-operative independence and complication which lead to healthcare cost savings.

Our findings should be considered within the context of this feasibility study design. This study addresses the understudied area of post-THA rehabilitation of patients 60 years or younger. A strength of this study was including objective and subjective measures of PA as well as examining the correlation between these two measures. We showed the feasibility of implementing an augmented rehabilitation program (including land and water-based exercise) in THA patients who are 60 years or younger and support a definitive trial.

Although this study had insufficient power to detect change with some outcomes, the reported change will be valuable in sample size calculations for larger trials. The long-term sustainability of the program is unknown, and recommendations for a 6-month follow-up may be warranted given that other post-operative rehabilitation programs for THA have reported sustained change for 6 months (48). Although the control group was age and sex-matched, a randomized control trial is recommended to identify any congruent findings.

\section{Conclusion}

The post-operative augmented rehabilitation program for younger patients with THA may lead to an immediate increase in step counts, MVPA bouts, self-reported function, and pain reduction. The findings provide insights into the pragmatic issues of implementing a land and water-based rehabilitation program for younger patients. Further study with a large sample and long-term follow-up is warranted to assess the long-term effects of our augmented rehabilitation program.

\section{Abbreviations}

THA: Total Hip Arthroplasty

PA: Physical Activity

SWA: Sense Wear Pro Armband ${ }^{\mathrm{TM}}$

HOOS: Hip Osteoarthritis Outcome Score

OA: Osteoarthritis

ROM: Range Of Motion

Nm: Nanometer

ADL: Activities of Daily Living

MET: Metabolic Equivalent Task

Page 12/18 
MVPA: Moderate-Vigorous Physical Activity

MVPA $_{a l l}$ :Total Minutes Of Moderate-Vigorous Physical Activity

MVPA $_{10+}$ : continuous Moderate-Vigorous Physical Activity occurring in $>10$ minutes bouts

Sport/Rec: Sport and Recreation

QoL: Quality of life

SD: standard deviation

CSEP: Canadian Society for Exercise Physiology

\section{Declarations}

\section{Ethics approval and consent to participate}

This study was approved by the University of Alberta's Health Ethics Board. (PRO00051978). Written informed consent was obtained from all participants prior to this study. All procedures were performed in accordance with University of Alberta's Health Ethics Board guidelines.

\section{Consent for publication}

Not applicable.

\section{Availability of data and materials}

The datasets during and/or analyzed during the current study available from the corresponding author on reasonable request.

\section{Competing interests}

The authors declare that they have no competing interests.

\section{Funding}

This study was not funded. Ahmed Negm was funded by the Alberta Innovates Postdoctoral fellowship Award

\section{Authors' Contributions}

All authors have read and approved the manuscript. Conception/Design: CAJ and RH. Acquisition and Analysis: AMN, GSJ, CAJ. Interpretation: AMN, MY, GSJ, RH, CAJ. Draft and Revision: AMN, MY, GSJ, RH, CAJ. 


\section{Acknowledgments}

The authors thank Sofia Campione, Holly Kinnear, Colleen O'Leary, and Allie Wait for their assistance with recruitment.

\section{References}

1. ClHI. Hip and Knee Replacements in Canada, 2016-2017: Canadian Joint Replacement Registry Annual Report. Ottawa, ON; 2018.

2. Kurtz SM, Lau E, Ong K, Zhao K, Kelly M, Bozic KJ. Future young patient demand for primary and revision joint replacement: national projections from 2010 to 2030. Clin Orthop Relat Res. 2009;467(10):2606-12.

3. Kurtz S, Mowat F, Ong K, Chan N, Lau E, Halpern M. Prevalence of primary and revision total hip and knee arthroplasty in the United States from 1990 through 2002. J Bone Joint Surg Am. 2005;87(7):1487-97.

4. Kuijpers MFL, Hannink G, van Steenbergen LN, Schreurs BW. Total Hip Arthroplasty in Young Patients in The Netherlands: Trend Analysis of $>19,000$ Primary Hip Replacements in the Dutch Arthroplasty Register. J Arthroplasty. 2018;33(12):3704-11.

5. Lespasio MJ, Sultan AA, Piuzzi NS, Khlopas A, Husni ME, Muschler GF, et al. Hip Osteoarthritis: A Primer. Perm J. 2018;22:17-084.

6. Studers P, Belajevs D, Jurkevics V, Likums P. Ten to fifteen-year clinical and radiographic follow-up with a third-generation cementless stem in a young patient population. Int Orthop. 2016;40(3):465-71.

7. Sedrakyan A, Romero L, Graves S, Davidson D, de Steiger R, Lewis P, et al. Survivorship of hip and knee implants in pediatric and young adult populations: analysis of registry and published data. $\mathrm{J}$ Bone Joint Surg Am. 2014;96 Suppl 1:73-8.

8. Mancuso CA, Ranawat CS, Esdaile JM, Johanson NA, Charlson ME. Indications for total hip and total knee arthroplasties. Results of orthopaedic surveys. J Arthroplasty. 1996;11(1):34-46.

9. Eskelinen A, Remes V, Helenius I, Pulkkinen P, Nevalainen J, Paavolainen P. Uncemented total hip arthroplasty for primary osteoarthritis in young patients: a mid-to long-term follow-up study from the Finnish Arthroplasty Register. Acta Orthop. 2006;77(1):57-70.

10. Röder C, Parvizi J, Eggli S, Berry DJ, Müller ME, Busato A. Demographic factors affecting long-term outcome of total hip arthroplasty. Clin Orthop Relat Res. 2003(417):62-73.

11. Matharu GS, McBryde CW, Pynsent WB, Pynsent PB, Treacy RB. The outcome of the Birmingham Hip Resurfacing in patients aged $<50$ years up to 14 years post-operatively. Bone Joint J. 2013;95-B(9):1172-7.

12. McAuley JP, Szuszczewicz ES, Young A, Engh CA. Total hip arthroplasty in patients 50 years and younger. Clin Orthop Relat Res. 2004(418):119-25.

13. Coulter CL, Scarvell JM, Neeman TM, Smith PN. Physiotherapist-directed rehabilitation exercises in the outpatient or home setting improve strength, gait speed and cadence after elective total hip replacement: a systematic review. J Physiother. 2013;59(4):219-26.

14. Wang AW, Gilbey HJ, Ackland TR. Perioperative exercise programs improve early return of ambulatory function after total hip arthroplasty: a randomized, controlled trial. Am J Phys Med Rehabil. 2002;81(11):801-6. 
15. Trudelle-Jackson E, Emerson R, Smith S. Outcomes of total hip arthroplasty: a study of patients one year postsurgery. J Orthop Sports Phys Ther. 2002;32(6):260-7.

16. Husby VS, Helgerud J, Bjørgen S, Husby OS, Benum P, Hoff J. Early postoperative maximal strength training improves work efficiency 6-12 months after osteoarthritis-induced total hip arthroplasty in patients younger than 60 years. Am J Phys Med Rehabil. 2010;89(4):304-14.

17. Jones CA, Pohar S. Health-related quality of life after total joint arthroplasty: a scoping review. Clin Geriatr Med. 2012;28(3):395-429.

18. Nilsdotter AK, Toksvig-Larsen S, Roos EM. Knee arthroplasty: are patients' expectations fulfilled? A prospective study of pain and function in 102 patients with 5-year follow-up. Acta Orthop. 2009;80(1):55-61.

19. Harding P, Holland AE, Delany C, Hinman RS. Do activity levels increase after total hip and knee arthroplasty? Clin Orthop Relat Res. 2014;472(5):1502-11.

20. de Groot IB, Bussmann HJ, Stam HJ, Verhaar JA. Small increase of actual physical activity 6 months after total hip or knee arthroplasty. Clinical Orthopaedics and Related Research. 2008;466(9):2201-8.

21. Zhang W, Doherty M, Peat G, Bierma-Zeinstra MA, Arden NK, Bresnihan B, et al. EULAR evidence-based recommendations for the diagnosis of knee osteoarthritis. Ann Rheum Dis. 2010;69(3):483-9.

22. Jakicic JM, Marcus M, Gallagher KI, Randall C, Thomas E, Goss FL, et al. Evaluation of the SenseWear Pro Armband to assess energy expenditure during exercise. Med Sci Sports Exerc. 2004;36(5):897-904.

23. Wetten AA, Batterham M, Tan SY, Tapsell L. Relative validity of 3 accelerometer models for estimating energy expenditure during light activity. J Phys Act Health. 2014;11(3):638-47.

24. Malavolti M, Pietrobelli A, Dugoni M, Poli M, Romagnoli E, De Cristofaro P, et al. A new device for measuring resting energy expenditure (REE) in healthy subjects. Nutr Metab Cardiovasc Dis. 2007;17(5):338-43.

25. Cole PJ, LeMura LM, Klinger TA, Strohecker K, McConnell TR. Measuring energy expenditure in cardiac patients using the Body Media Armband versus indirect calorimetry. A validation study. J Sports Med Phys Fitness. 2004;44(3):262-71.

26. Nilsdotter AK, Lohmander LS, Klassbo M, Roos EM. Hip disability and osteoarthritis outcome score (HOOS)-validity and responsiveness in total hip replacement. BMC Musculoskelet Disord. 2003;4:10.

27. Fruin ML, Rankin JW. Validity of a multi-sensor armband in estimating rest and exercise energy expenditure. Med Sci Sports Exerc. 2004;36(6):1063-9.

28. King GA, Torres N, Potter C, Brooks TJ, Coleman KJ. Comparison of activity monitors to estimate energy cost of treadmill exercise. Med Sci Sports Exerc. 2004;36(7):1244-51.

29. St-Onge M, Mignault D, Allison DB, Rabasa-Lhoret R. Evaluation of a portable device to measure daily energy expenditure in free-living adults. Am J Clin Nutr. 2007;85(3):742-9.

30. Johannsen DL, Calabro MA, Stewart J, Franke W, Rood JC, Welk GJ. Accuracy of armband monitors for measuring daily energy expenditure in healthy adults. Med Sci Sports Exerc. 2010;42(11):2134-40.

31. Matthews CE, Ainsworth BE, Thompson RW, Bassett DR. Sources of variance in daily physical activity levels as measured by an accelerometer. Med Sci Sports Exerc. 2002;34(8):1376-81.

32. Matthews CE, Chen KY, Freedson PS, Buchowski MS, Beech BM, Pate RR, et al. Amount of time spent in sedentary behaviors in the United States, 2003-2004. American journal of epidemiology. 2008;167(7):87581. 
33. Troiano RP, Berrigan D, Dodd KW, Masse LC, Tilert T, McDowell M. Physical activity in the United States measured by accelerometer. Medicine and science in sports and exercise. 2008;40(1):181-8.

34. White DK, Wagenaar RC, Ellis T. Monitoring activity in individuals with Parkinson disease: a validity study. J Neurol Phys Ther. 2006;30(1):12-21.

35. Lim I, van Wegen E, Jones D, Rochester L, Nieuwboer A, Willems AM, et al. Does cueing training improve physical activity in patients with Parkinson's disease? Neurorehabil Neural Repair. 2010;24(5):469-77.

36. Dogra S, Stathokostas L. Sedentary behavior and physical activity are independent predictors of successful aging in middle-aged and older adults. Journal of aging research. 2012;2012:190654.

37. Pate RR, O'Neill JR, Lobelo F. The evolving definition of" sedentary". Exercise and sport sciences reviews. 2008;36(4):173-8.

38. Tremblay MS, Aubert S, Barnes JD, Saunders TJ, Carson V, Latimer-Cheung AE, et al. Sedentary Behavior Research Network (SBRN) - Terminology Consensus Project process and outcome. Int J Behav Nutr Phys Act. 2017;14(1):75.

39. Garber CE, Blissmer B, Deschenes MR, Franklin BA, Lamonte MJ, Lee IM, et al. American College of Sports Medicine position stand. Quantity and quality of exercise for developing and maintaining cardiorespiratory, musculoskeletal, and neuromotor fitness in apparently healthy adults: guidance for prescribing exercise. Medicine and science in sports and exercise. 2011;43(7):1334-59.

40. Haskell WL, Lee IM, Pate RR, Powell KE, Blair SN, Franklin BA, et al. Physical activity and public health: updated recommendation for adults from the American College of Sports Medicine and the American Heart Association. Circulation. 2007;116(9):1081-93.

41. Colley RC, Garriguet D, Janssen I, Craig CL, Clarke J, Tremblay MS. Physical activity of Canadian adults: accelerometer results from the 2007 to 2009 Canadian Health Measures Survey. Health Rep. 2011;22(1):714.

42. Klässbo M, Larsson E, Mannevik E. Hip disability and osteoarthritis outcome scoreAn extension of the Western Ontario and McMaster Universities Osteoarthritis Index. Scandinavian Journal of Rheumatology. 2003;32(1):46-51.

43. Thorborg K, Roos EM, Bartels EM, Petersen J, Holmich P. Validity, reliability and responsiveness of patientreported outcome questionnaires when assessing hip and groin disability: a systematic review. British Journal of Sports Medicine. 2010;44(16):1186-96.

44. Suarez-Almazor ME, Looney C, Liu Y, Cox V, Pietz K, Marcus DM, et al. A randomized controlled trial of acupuncture for osteoarthritis of the knee: effects of patient-provider communication. Arthritis Care Res (Hoboken). 2010;62(9):1229-36.

45. Schober P, Boer C, Schwarte LA. Correlation Coefficients: Appropriate Use and Interpretation. Anesthesia \& Analgesia. 2018;126(5):1763-8.

46. Tudor-Locke C, Craig CL, Aoyagi Y, Bell RC, Croteau KA, De Bourdeaudhuij I, et al. How many steps/day are enough? For older adults and special populations. Int J Behav Nutr Phys Act. 2011;8:80.

47. Lyman S, Lee YY, McLawhorn AS, Islam W, MacLean CH. What Are the Minimal and Substantial Improvements in the HOOS and KOOS and JR Versions After Total Joint Replacement? Clin Orthop Relat Res. 2018;476(12):2432-41. 
48. Crizer MP, Kazarian GS, Fleischman AN, Lonner JH, Maltenfort MG, Chen AF. Stepping Toward Objective Outcomes: A Prospective Analysis of Step Count After Total Joint Arthroplasty. J Arthroplasty. 2017;32(9S):S162-S5.

49. Fujita K, Makimoto K, Tanaka R, Mawatari M, Hotokebuchi T. Prospective study of physical activity and quality of life in Japanese women undergoing total hip arthroplasty. J Orthop Sci. 2013;18(1):45-53.

50. Hammett T, Simonian A, Austin M, Butler R, Allen KD, Ledbetter L, et al. Changes in Physical Activity After Total Hip or Knee Arthroplasty: A Systematic Review and Meta-Analysis of Six- and Twelve-Month Outcomes. Arthritis Care Res (Hoboken). 2018;70(6):892-901.

51. CSEP. Canadian Physical Activity Guidelines For Older Adults. 2014. Contract No.: July 20, 2020.

52. Lemmey A, Okoro T. The efficacy of exercise rehabilitation in restoring physical function following total hip replacement for osteoarthritis: a review. OA Musculoskeletal Medicine. 2013;Jul 01(1):2-13.

53. Barker AL, Talevski J, Morello RT, Brand CA, Rahmann AE, Urquhart DM. Effectiveness of aquatic exercise for musculoskeletal conditions: a meta-analysis. Arch Phys Med Rehabil. 2014;95(9):1776-86.

54. Edlich RF, Towler MA, Goitz RJ, Wilder RP, Buschbacher LP, Morgan RF, et al. Bioengineering principles of hydrotherapy. J Burn Care Rehabil. 1987;8(6):580-4.

55. Becker BE. Aquatic therapy: scientific foundations and clinical rehabilitation applications. PM R. 2009;1(9):859-72.

56. Batterham SI, Heywood S, Keating JL. Systematic review and meta-analysis comparing land and aquatic exercise for people with hip or knee arthritis on function, mobility and other health outcomes. BMC Musculoskelet Disord. 2011;12:123.

57. Strath SJ, Kaminsky LA, Ainsworth BE, Ekelund U, Freedson PS, Gary RA, et al. Guide to the assessment of physical activity: Clinical and research applications: a scientific statement from the American Heart Association. Circulation. 2013;128(20):2259-79.

58. Blikman T, Stevens M, Bulstra SK, van den Akker-Scheek I, Reininga IH. Reliability and validity of the Dutch version of the International Physical Activity Questionnaire in patients after total hip arthroplasty or total knee arthroplasty. J Orthop Sports Phys Ther. 2013;43(9):650-9.

59. Loprinzi PD, Davis RE. Bouted and non-bouted moderate-to-vigorous physical activity with health-related quality of life. Prev Med Rep. 2016;3:46-8.

60. Anokye NK, Trueman P, Green C, Pavey TG, Taylor RS. Physical activity and health related quality of life. BMC Public Health. 2012;12:624.

61. Fortina M, Carta S, Gambera D, Crainz E, Ferrata P, Maniscalco P. Recovery of physical function and patient's satisfaction after total hip replacement (THR) surgery supported by a tailored guide-book. Acta Biomed. 2005;76(3):152-6.

62. Beaupre LA, Masson EC, Luckhurst BJ, Arafah O, O'Connor GJ. A randomized pilot study of a comprehensive postoperative exercise program compared with usual care following primary total hip arthroplasty in subjects less than 65 years of age: feasibility, selection of outcome measures and timing of assessment. BMC Musculoskelet Disord. 2014;15:192.

63. Ginsburg GS, Phillips KA. Precision Medicine: From Science To Value. Health Aff (Millwood). 2018;37(5):694-701. 
Figures

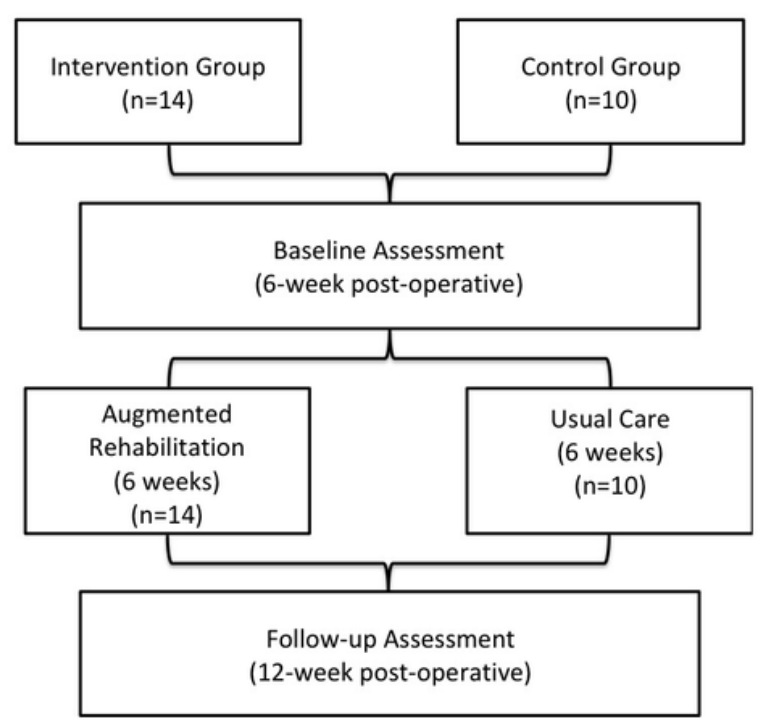

Figure 1

Study Flow chart 